\section{Setting the record straight}

SIR - The review of Equivalence and Priority: Newton versus Leibniz by William R. Shea (Nature 364, 681; 1993) contains serious factual misrepresentations of my work on Leibniz and Newton's Principia. Shea claims that the new evidence in my book rests on a reading of just two manuscript sheets by Leibniz, together with the fact that one of them has a watermark of a type used by Leibniz in Vienna in 1688. On the basis of this "slender evidence", he says, I conclude that Leibniz saw the Principia in that city in that year and overlook the fact that Leibniz could have easily carried old paper with him and used in 1690 a sheet acquired a couple of years earlier. Hence my belief, contrary to Leibniz's own claims, that he saw the 1687 Principia before publishing his reply in 1689 would be unjustified.

This is not so much a charge of poor scholarship as one of lack of common sense. However, on p. 96 of my book I outline the criteria I have adopted for dating Leibniz's manuscript essays. After stating that "all watermarked manuscripts discussed in this chapter are of a type used by Leibniz in Vienna in 1688", I add that "this element alone does not prove that the essays date from 1688, since Leibniz could have carried some Viennese paper with him". I also add that my "second criterion involves the conceptual development of Leibniz's theory and terminology employed, and provides a firmer basis for the dating". Indeed, my work is based on an extensive investigation of several dozen manuscripts by Leibniz which are listed in Appendix 3. Moreover, I publish six of them for the first time, discussing the issues of priority and publication in a seventeenth-century context, and providing an extensive analysis of the background, formation, and reception of Leibniz's response to Newton.

Domenico Bertoloni Meli

Jesus College, Cambridge CB5 8BL, UK

\section{Allain defended}

SIR - Badrig Mélékian (Nature 365, 289; 1993) repeats two of the myths of the "Paris blood scandal". He asserts that Dr Jean-Pierre Allain deliberately provided patients with infected material. This is untrue. Allain's problem at the beginning of 1985 was in convincing others of the urgency of the situation; haemophiliacs were found to be seropositive against HIV, but the full significance of this seropositivity in terms of infection was not clear at that time either to him (see his paper in Blood 66, 896-901; 1985), or to others (see the leading article by Montagnier et al. Presse Médicale 14, 1451; 1985). The active steps Allain took to speed the introduction of safety measures in the period January-June 1985 have been detailed in the Lancet (342, 332-333; 24 July 1993). More recently, letters have arrived from Professor Gluckman and Dr BarréSinoussi of Paris who were as wellinformed as anyone in the world at that time; both tell of the careful and concerned consultations that took place in early 1985 that led to the effective measures of June 1985.

Between June and October 1985, nonheat-treated pooled plasma continued to be given to seropositive haemophiliacs. But this was the result of an independent decision of the National Advisory Committee on Blood Transfusion (CCTS) made on the basis of the best knowledge of that time. Even in retrospect, this decision seems not unreasonable; furthermore, it was a consensus decision of first-class professionals and did not involve Allain.

There were not "hundreds and maybe thousands" infected during this period; the great majority of infections occurred before the end of 1984 , before there was an awareness of the problem and before protective measures were available. That any infections at all occurred is a matter of profound regret, none more so than to Jean-Pierre Allain who is known to all who have worked with him as a caring and thoughtful physician, both before, during and after the events of 1985 .

\section{Robin Carrell}

University of Cambridge,

Department of Haematology,

MRC Centre, Hills Road,

Cambridge CB2 2QH, UK

\section{Korean women}

SIR - In response to your article on the rapid development of science and technology in South Korea (Nature 364, 379; 1993), I should like to mention the position of Korean women in those fields.

I grew up within the major science complexes in Korea. In 1980, when my father was president of the Korea Advanced Institute of Science and Technology, an application for a faculty position arrived from Massachusetts Institute of Technology. The application was taken seriously until it was realized that the applicant was a woman. In his whole career, my father has had only one female PhD student, and he had difficulty in finding her a job because there was a regulation against hiring female scientists in industry. The ban has since been lifted, but little else has changed.

Discrimination begins at a very early stage, as female students are often discouraged from pursuing careers in science (or any career at all, for that matter). If the situation is changing, the changes are occurring very slowly. It is a pity that the country disregards the potential and talents of half the population when it is so concerned about improving science and technology. I have watched the talents of many bright and capable women go to waste - my mother's friends included unemployed $\mathrm{PhDs}$ whose frustration was apparent.

Carol Lee

School of Oceanography WB-10, University of Washington,

Seattle, Washington 98195, USA

\section{When in Rome}

SIR - I should like to comment on "Know your Japanese host" (Nature 364, 376; 1993). There are at least two necessary conditions in order to profit from a long stay in a foreign country: (1) understanding of the language of the host country, and (2) interest in its culture.

The primacy of the English language in the scientific community is undeniable, but English-speaking scientists will be at a disadvantage if they set out without consideration of the above factors, not only in their professional activity but also in their daily life in a foreign country.

It is not always easy to master a foreign language, but Japanese is not quite such a difficult language as your article suggests. The difficulty of Japanese for the English should be exactly the same that of English for the Japanese. Most Japanese scientists work hard to learn foreign languages, not only English, before they go abroad. It is neither fair nor useful to blame the lack of ability in English of Japanese students (Nature 362, 387; 1993) without mentioning the inability of students from elsewhere to speak Japanese.

It is certainly true that "international exchange between Japanese and foreign researchers would benefit both groups" (Nature 340, 337; 1989) but this may be achieved only by effort on both sides, based on fellowship and mutual understanding of cultures.

Nobuzo Terao

Catholic University of Louvain,

21 rue de l'Angélique,

B-1348 Louvain-la-Neuve, Belgium

\section{Prudent fellow}

SIR - It's difficult to say this diplomatically, but, judging by the tone of Stuart Sutherland's review of $B$. F. Skinner: $A$ Life (Nature 364, 767; 1993), perhaps Skinner's avoidance of the edge of Magdalen Tower was, in the circumstances, not so much acrophobia as good sense.

Robert E. Adler

39560 Stevenson Place, Suite 215,

Fremont, California 94539, USA

NATURE · VOL 365 - 14 OCTOBER 1993 